\title{
Tailor-Made Engineering of Bioinspired Inks for Writing Barcode-Like Multifunctional Sensory Electronics
}

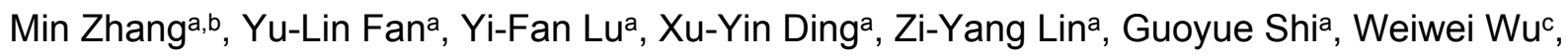 \\ Hossam Haick ${ }^{\text {b,c* }}$ \\ a School of Chemistry and Molecular Engineering, Shanghai Key Laboratory for Urban Ecological \\ Processes and Eco-Restoration, Shanghai Key Laboratory of Green Chemistry and Chemical \\ Processes, East China Normal University, Shanghai 200241, China. \\ ${ }^{b}$ Department of Chemical Engineering and Russell Berrie Nanotechnology Institute, Technion - \\ Israel Institute of Technology, Haifa 320003, Israel. \\ c School of Advanced Materials and Nanotechnology, Xidian University, Shaanxi 710126, China.
}

Chemicals. Synthetic graphite power was purchased from BDH chemicals Ltd. (Poole, England). Dopamine hydrochloride, 1-Dodecanthiol, $1 \mathrm{H}, 1 \mathrm{H}, 2 \mathrm{H}, 2 \mathrm{H}$-Perfluorodecanethiol, aniline, oleylamine, polyethyleneimine (branched, average $\mathrm{Mw} \sim 25,000$ by LS) were ordered from Sigma-Aldrich, Inc. All chemicals used in the presented work were obtained from commercial sources and directly used without further purification. The substrates, including Kapton, aluminium foil, nitrile gloves, PDMS, glass and Teflon, were cleaned with ethanol prior to printing. No other surface treatment was used.

Instrumentation. Contact angle measurements were performed using the ramé-hart Model 200 Standard Contact Angle Goniometer. The colloidal viscosity of P@G ink was examined by the Physica MCR 501 rheometer. The photoconductivity was measured by a Keithley meter under illumination by a full-spectrum high power LED chip (https://www.ebay.com/itm/Full-Spectrum-High-Power-LEDChip-Grow-Light-3W-100W-380-840NM-FUll-spectrum-

1262764518753? var=\&hash=item3d2dfc5d61). Thorlabs S310C system was used to calibrate the optical power density $\left(\mathrm{mW} \mathrm{cm}^{-2}\right)$ of the full-spectrum high power LED chip.

Preparation of graphene oxide. Briefly, graphite $(2 \mathrm{~g})$ was added into a mixture of concentrated $\mathrm{H}_{2} \mathrm{SO}_{4}(80 \mathrm{~mL}), \mathrm{K}_{2} \mathrm{~S}_{2} \mathrm{O}_{8}(7 \mathrm{~g})$ and $\mathrm{P}_{2} \mathrm{O}_{5}(5 \mathrm{~g})$. The mixture was heated to $80^{\circ} \mathrm{C}$ for $5 \mathrm{~h}$, and then diluted with water and left overnight. After that, the product was collected by centrifugation. This solid was re-oxidized by another oxidation treatment. The as-prepared product, as well as $\mathrm{NaNO}_{3}(1 \mathrm{~g})$, was mixed with $\mathrm{H}_{2} \mathrm{SO}_{4}(95 \%, 48 \mathrm{~mL})$ in a $250 \mathrm{~mL}$ flask and stirred for $30 \mathrm{~min}$ in an ice-bath. Then, $\mathrm{KMnO}_{4}$ $(6 \mathrm{~g})$ was gradually added to the suspension under vigorous stirring. The ice-bath was removed and the mixture stirred at $35^{\circ} \mathrm{C}$ for $5 \mathrm{~h}$. Deionized water $(60 \mathrm{~mL})$ was slowly added to the paste under vigorous stirring. The reaction temperature was increased to $98^{\circ} \mathrm{C}$, and the sample maintained for 2 $\mathrm{h}$ at this temperature. Finally, $\mathrm{H}_{2} \mathrm{O}_{2}(30 \%, 20 \mathrm{~mL})$ was added to the mixture. The mixture was washed with $\mathrm{HCl}(5 \% \mathrm{w} / \mathrm{v})$ and deionized water several times to obtain graphene oxide (GO), which was duly collected by centrifugation and dried under vacuum at $60^{\circ} \mathrm{C}$ for $6 \mathrm{~h}$. 
Preparation of polydopamine/reduced graphene oxide (P@G) conjugate. The procedure for the preparation of polydopamine/reduced graphene oxide (P@G) conjugate was according to our previous work (Nat. Commun. 2019, 10, 1120). In a typical synthesis, $25 \mathrm{mg}$ dopamine hydrochloride dissolved in $20 \mathrm{~mL}$ of water was mixed with $5 \mathrm{~mL}$ of $5 \mathrm{mg} / \mathrm{mL} \mathrm{GO}$ (pH adjusted to 8.5). The mixture was kept in a Teflon-lined autoclave at $160^{\circ} \mathrm{C}$ for $12 \mathrm{~h}$. After hydrothermal reaction, the autoclave was cooled to room temperature and the product of polydopamine/reduced graphene oxide (P@G) conjugate was washed in deionized water and ethanol several times, collected by centrifuge, and redispersed in ethanol for further use to form $P @ G$ ink.

Preparation of ligand-modified P@G inks. P@G ink was dispersed in ethanol and the pH was adjusted to 8.5 using alkaline ethanol solution. Thiol or $\mathrm{NH}_{2}$-containing compounds ( $\mathrm{T}_{1}$ : 1 Dodecanethiol, $\mathrm{T}_{2}$ : $1 \mathrm{H}, 1 \mathrm{H}, 2 \mathrm{H}, 2 \mathrm{H}-$ Perfluorodecanethiol, $\mathrm{N}_{1}$ : Aniline, $\mathrm{N}_{2}$ : Oleylamine, and $P$ : Polyethyleneimine) were respectively mixed with $\mathrm{P@G}$ ink and the mixtures kept for $12 \mathrm{~h}$ with gentle stirring. They were washed with ethanol several times, collected by centrifuge, and re-dispersed in ethanol for further use. They were named $T_{1}-P @ G$ ink, $T_{2}-P @ G$ ink, N $-P @ G$ ink, N $2-P @ G$ ink, and P-P@G ink, respectively.

Fabrication of barcode-like sensor array. The process of fabrication is shown in the figure below. A Kapton film was cut into small pieces with a $1 \mathrm{~cm} \times 2 \mathrm{~cm}$ size. Commercially available copper tapes were cut into small pieces with an approximate $0.2 \mathrm{~cm} \times 2 \mathrm{~cm}$ size and used as the alignment, and then paved alternatively onto the Kapton pieces to form six lanes (each $\sim 0.2 \mathrm{~cm}$ in width). Then $\sim 5$ $\mu \mathrm{L}$ of $4 \mathrm{mg} / \mathrm{mL} P @ G$ ink and chemical engineered $P @ G$ inks were written on the resulting lanes. After the ink dried, the copper tapes were peeled off and then six-channel ink lane were linked with aluminium foil strips using conductive silver paste at the linkages. Another two Kapton pieces were placed on either side of the as-prepared ink-involving Kapton piece and fixed them with tapes to form the barcode-like sensor array (BLSA).

Data Analysis. IBM SPSS 22.0 software was used to process principal component analysis (PCA). GraphPad Prism 7.0 software (San Diego, CA) was used to perform the data plotting. 
Table S1. Chemical ligands used for the functionalization of $P / G$ ink.

\begin{tabular}{|c|c|c|c|}
\hline No. & Name & $\mathrm{Mw}$ & Formula \\
\hline $\mathrm{T}_{1}$ & 1-Dodecanethiol & 202.4 & \\
\hline $\mathrm{T}_{2}$ & $1 \mathrm{H}, 1 \mathrm{H}, 2 \mathrm{H}, 2 \mathrm{H}-\mathrm{Perfluorodec}$ enethiol & 480.18 & \\
\hline $\mathrm{N}_{1}$ & Aniline & 93.13 & \\
\hline $\mathrm{N}_{2}$ & Oleylamine & 267.49 & \\
\hline$P$ & Polyethyleneimine, branched & $\sim 25,000$ & \\
\hline
\end{tabular}

Table S2. Name, molecular weight and chemical formula of the selected 12 kinds of VOCs.

\begin{tabular}{|c|c|c|}
\hline Name & $\mathrm{Mw}$ & Formula \\
\hline Heptanoic acid & 130.19 & \\
\hline Hexanoic acid & 116.16 & \\
\hline Heptanal & 114.18 & \\
\hline 1-Hexanol & 102.17 & \\
\hline Heptane & 100.2 & \\
\hline 2-Hexanone & 100.16 & \\
\hline Hexane & 86.18 & \\
\hline Isopropanol & 60.1 & \\
\hline
\end{tabular}
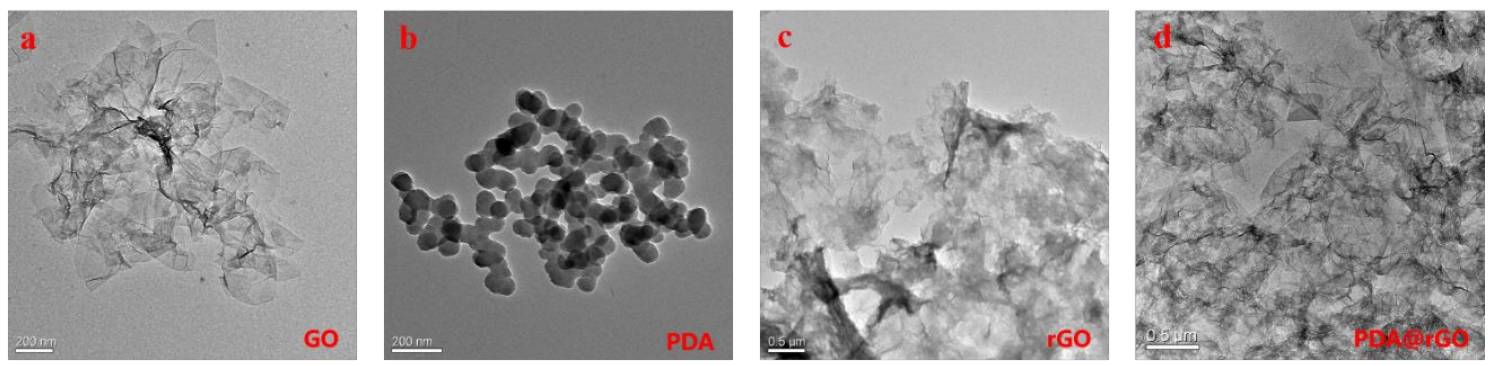

Fig. $\$ 1$ TEM images of GO (a), rGO (b), PDA (c), and P@G ink (d). 


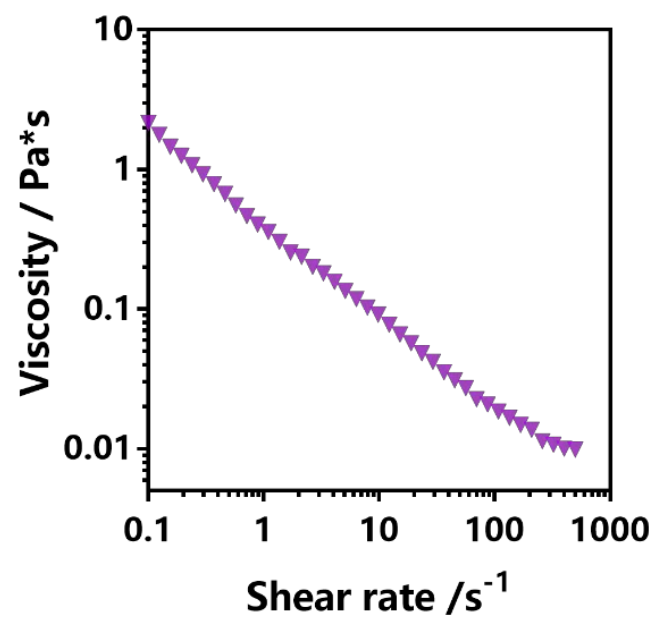

Fig. S2 Viscosity dependence as a function of shear rate for $P @ G$ ink.
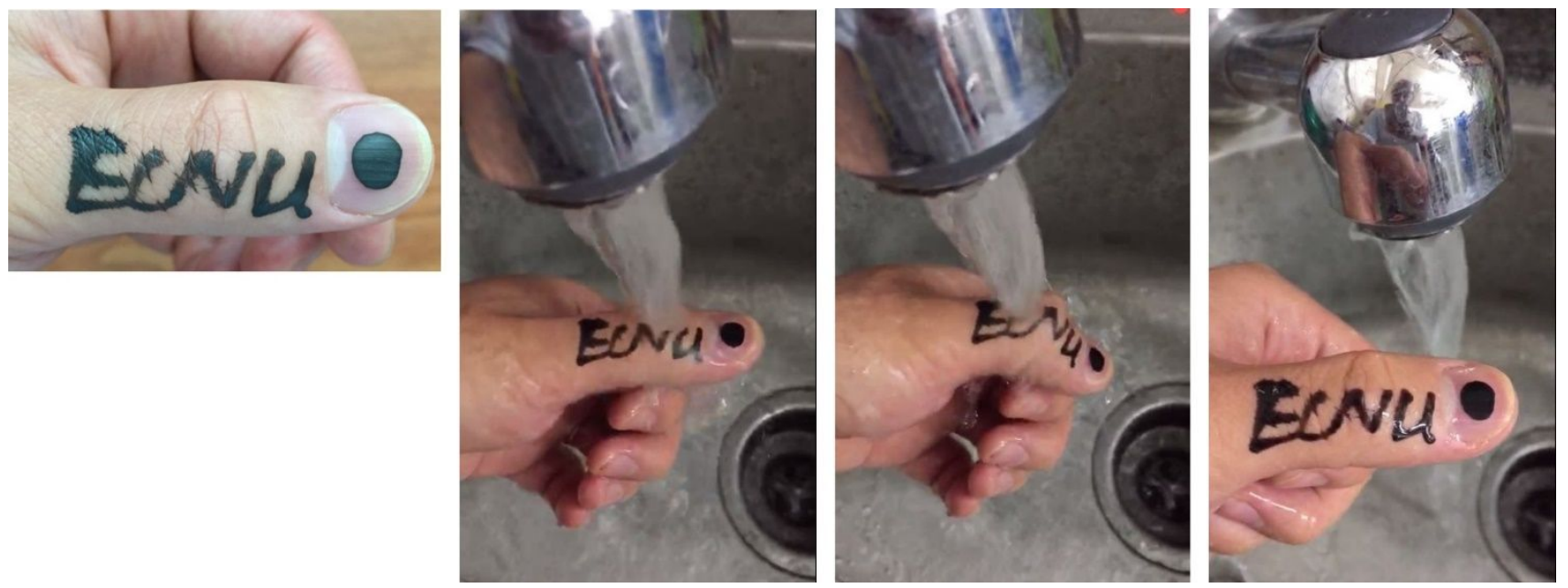

Fig. S3 P@G ink tattoo written on fingernails or skin is waterproof and wearable. 


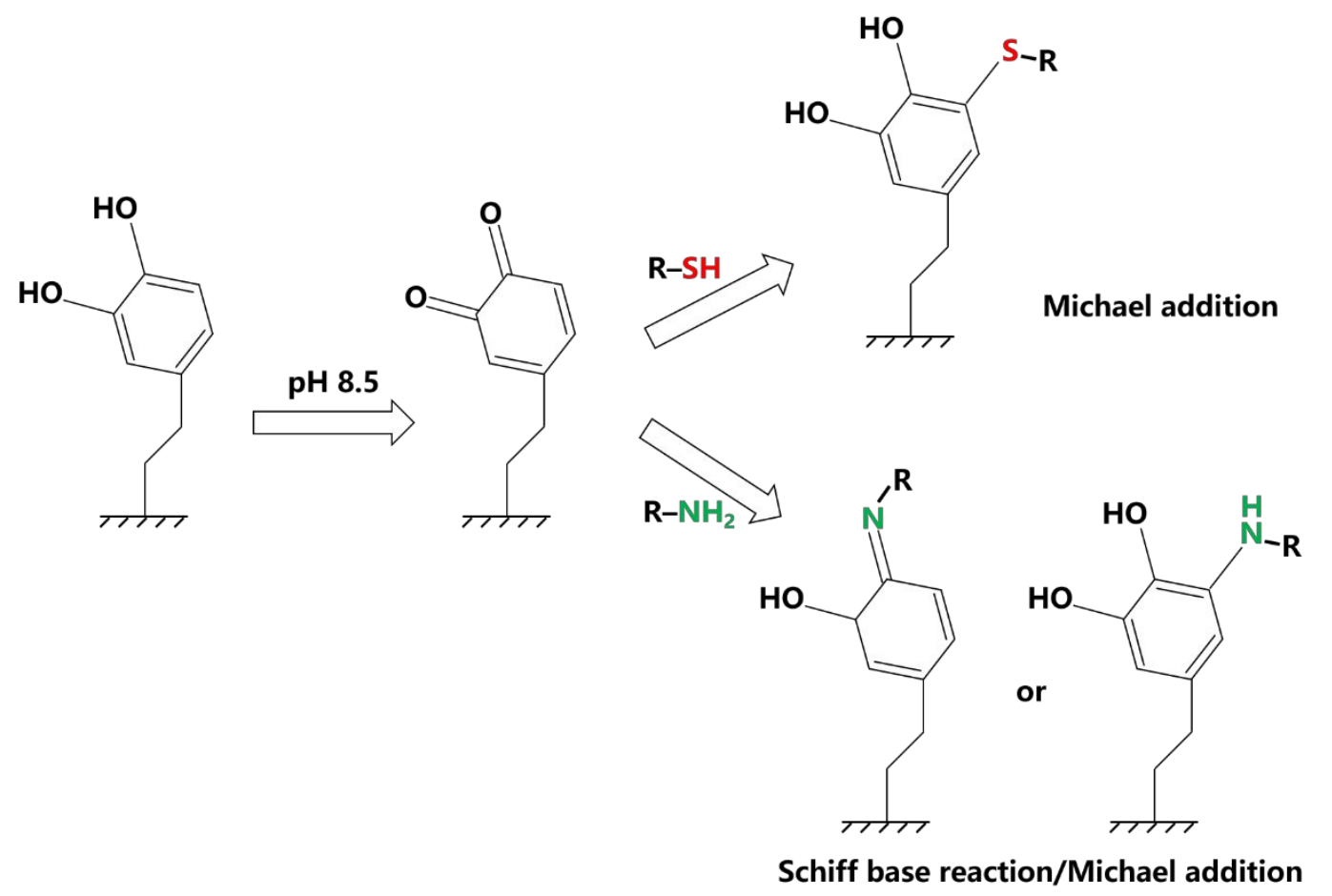

Fig. S4 The typical chemical reactions of PDA with thiol-containing compounds (via Michael addition) and amino-containing compounds (Schiff base reaction/Michael addition).
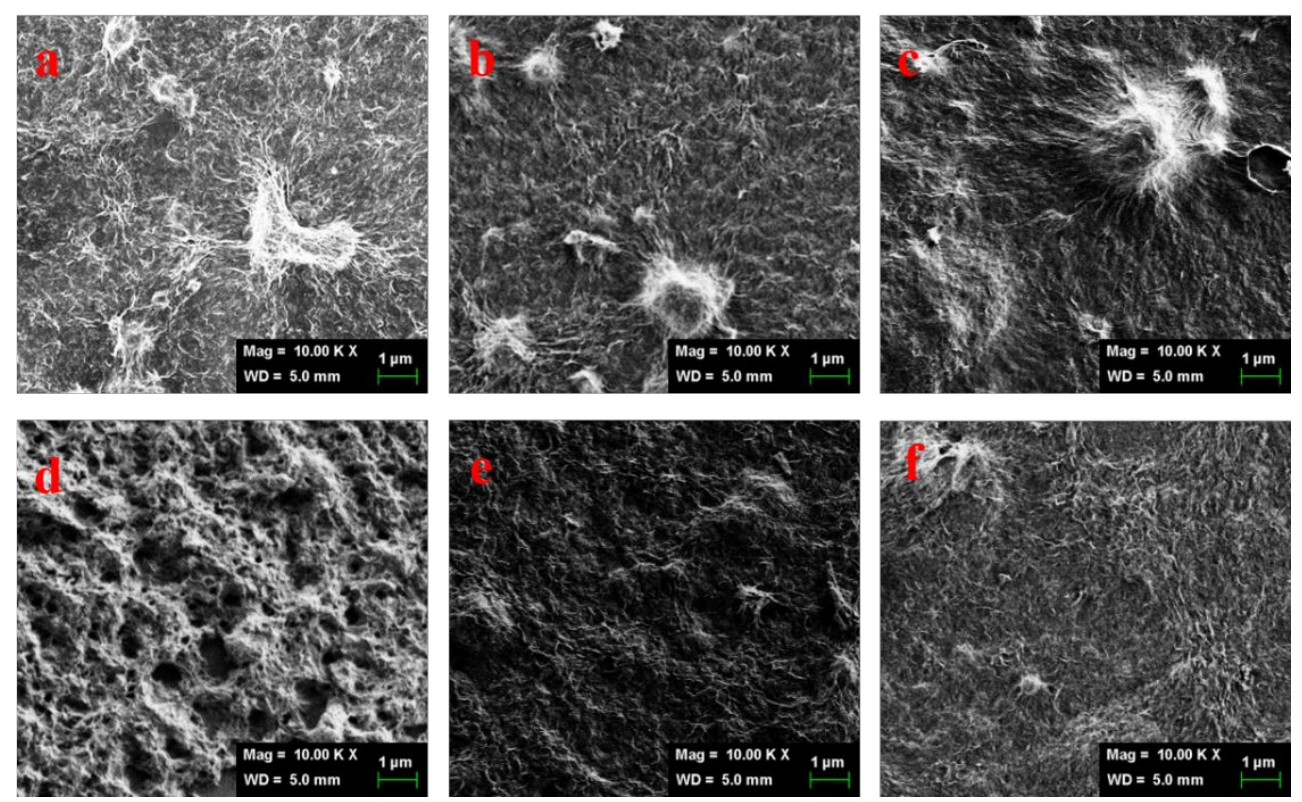

Fig. S5 SEM images of the surface morphology of deposited inks: (a) P@G ink, (b) T1-P@G ink, (c) $T_{2}-P @ G$ ink, (d) $N_{1}-P @ G$ ink, (e) $N_{2}-P @ G$ ink, and (f) P-P@G ink, respectively. 


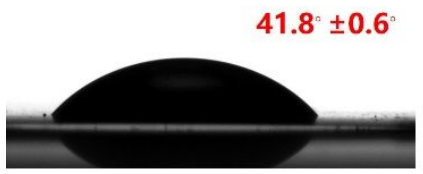

d

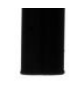

$\square$

$61.5^{\circ} \pm 0.37^{\circ}$

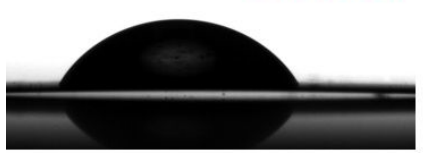

b

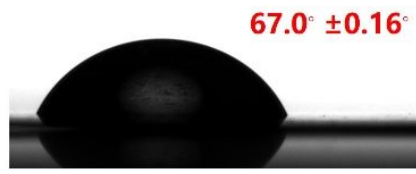

e

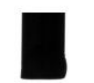

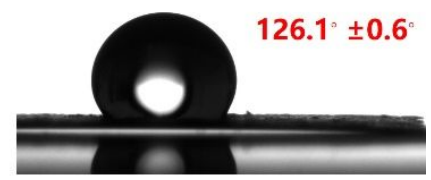

f

$\square$

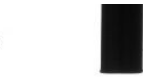

$47.4^{\circ} \pm 0.27$
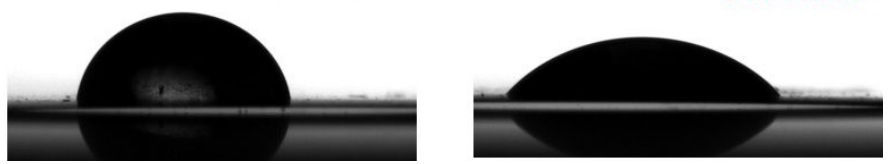

Fig. 56 Contact angle images of the surface morphology of deposited inks: (a) P@G ink, (b) $T_{1}-P @ G$ ink, (c) $T_{2}-P @ G$ ink, (d) $N_{1}-P @ G$ ink, (e) $N_{2}-P @ G$ ink, and (f) P-P@G ink, respectively.

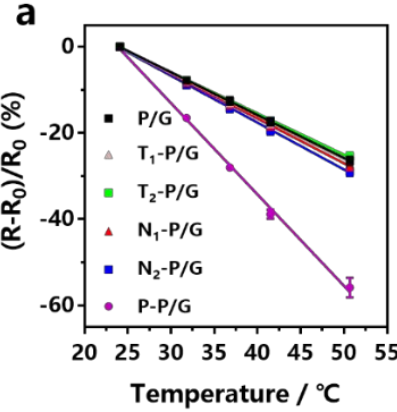

C

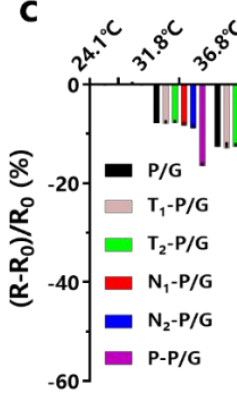

b

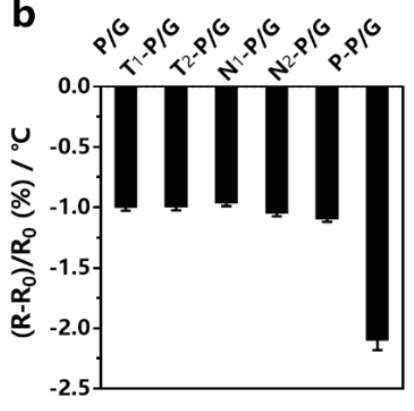

d

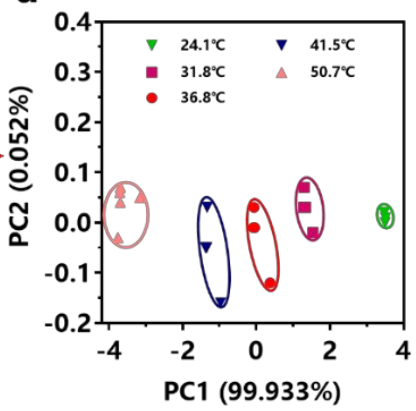

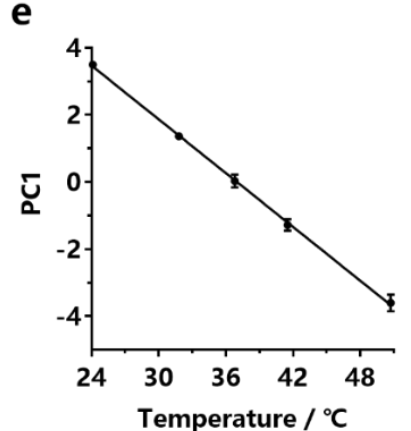

Fig. S7 The sensing performances of barcode-like sensor array (BLSA) toward temperature. a, Plots of different ink sensors in BLSA response to temperature from 24.1 to $50.7^{\circ} \mathrm{C}$ measured under constant humidity and light exposure. $\mathbf{b}$, Column diagram of different ink sensors' responses to per degree Celsius. $\mathbf{c},\left(\mathrm{R}-\mathrm{R}_{0}\right) / \mathrm{R}_{0^{-}}$ response pattern of BLSA against temperature. $d, 2 D$ canonical score plot for the $\left(R-R_{0}\right) / R_{0}$-response pattern as obtained from PCA against temperature. $\mathbf{e}$, Plot of the first discriminant factor (PC1) vs temperature. 

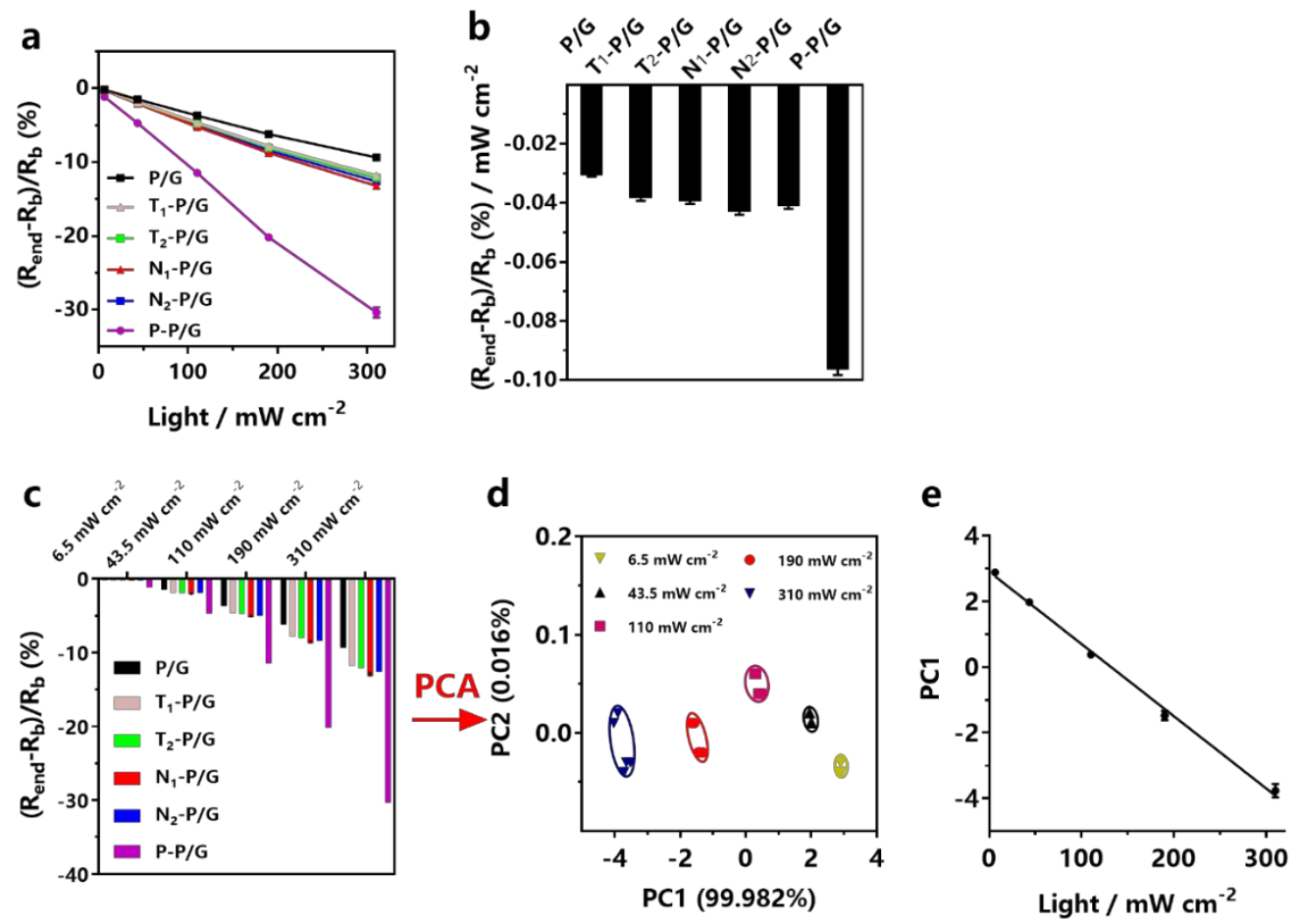

Fig. S8 The sensing performances of barcode-like sensor array (BPSA) toward light exposure. a, Plots of different ink sensors in BLSA response to light from 6.5 to $310 \mathrm{~mW} \mathrm{~cm}^{-2}$ measured under constant humidity and temperature. $\mathbf{b}$, Column diagram of different ink sensors' responses to per optical power density $\left(\mathrm{mW} \mathrm{cm}^{-}\right.$ $\left.{ }^{2}\right)$. c, $\left(R_{\text {end }}-R_{b}\right) / R_{b}$-response pattern of BLSA against light exposure. $d, 2 D$ canonical score plot for the $\left(R_{\text {end }}{ }^{-}\right.$ $\left.R_{b}\right) / R_{b}$-response pattern as obtained from PCA against light exposure. e, Plot of the first discriminant factor (PC1) vs light exposure.

a

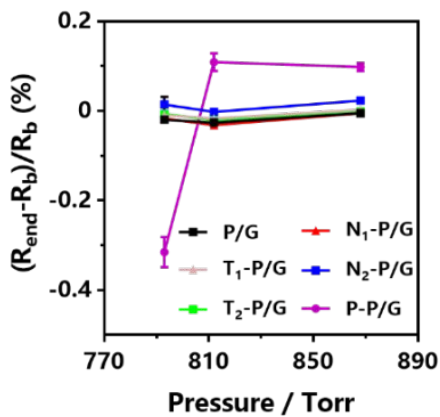

b

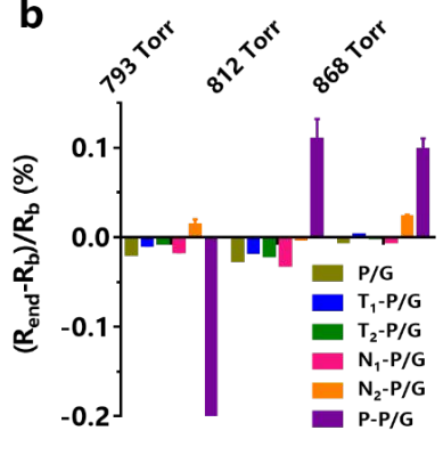

C

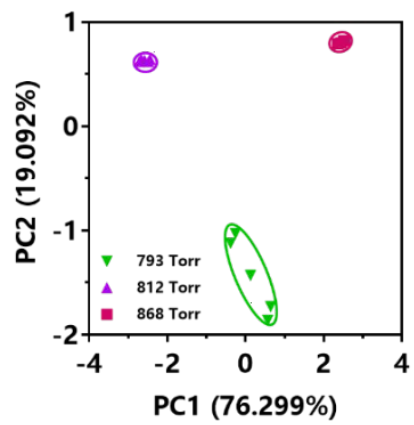

Fig. S9 The sensing performances of barcode-like sensor array (BLSA) toward air pressure. a, Plots of different ink sensors in BLSA in a stainless-steel chamber response to air pressure from 793 to 868 Torr controlled by gas generator under constant humidity and temperature. $b,\left(R_{\text {end }}-R_{b}\right) / R_{b}$-response pattern of $B L S A$ against air pressure. $c, 2 D$ canonical score plot for the $\left(R_{\text {end }}-R_{b}\right) / R_{b}$-response pattern as obtained from PCA against air pressure. 
a

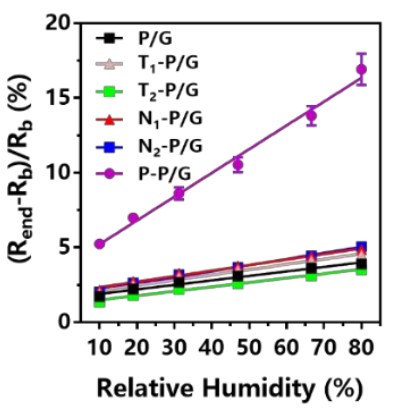

C

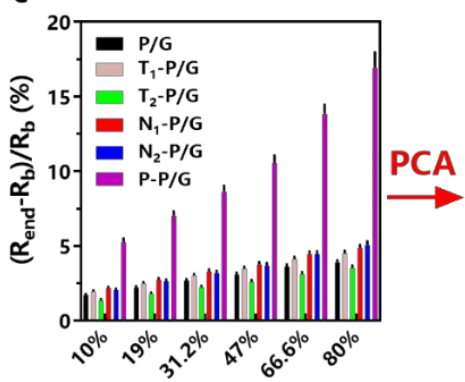

b

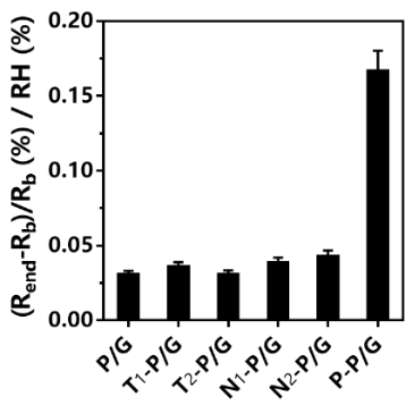

d

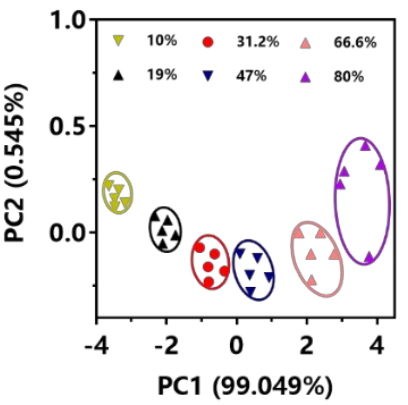

e

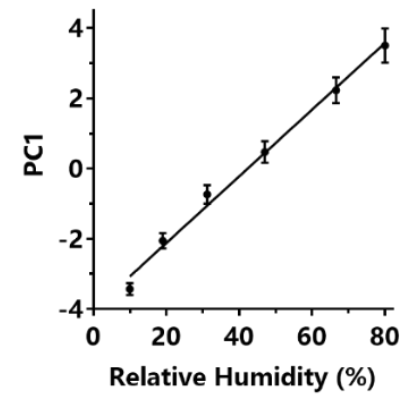

Fig. S10 The sensing performances of barcode-like sensor array (BLSA) toward relative humidity (RH). a, Plots of different ink sensors in BLSA in a stainless-steel chamber response to $\mathrm{RH}$ from 10 to $80 \%$ controlled by gas generator under constant temperature. $\mathbf{b}$, Column diagram of different sensors' responses to per RH. c, $\left(R_{\text {end }}-R_{b}\right) / R_{b}$-response pattern of BLSA against $R H$. d, 2D canonical score plot for the $\left(R_{\text {end }}-R_{b}\right) / R_{b}$-response pattern as obtained from PCA against $\mathrm{RH}$. e, Plot of the first discriminant factor (PC1) vs RH.
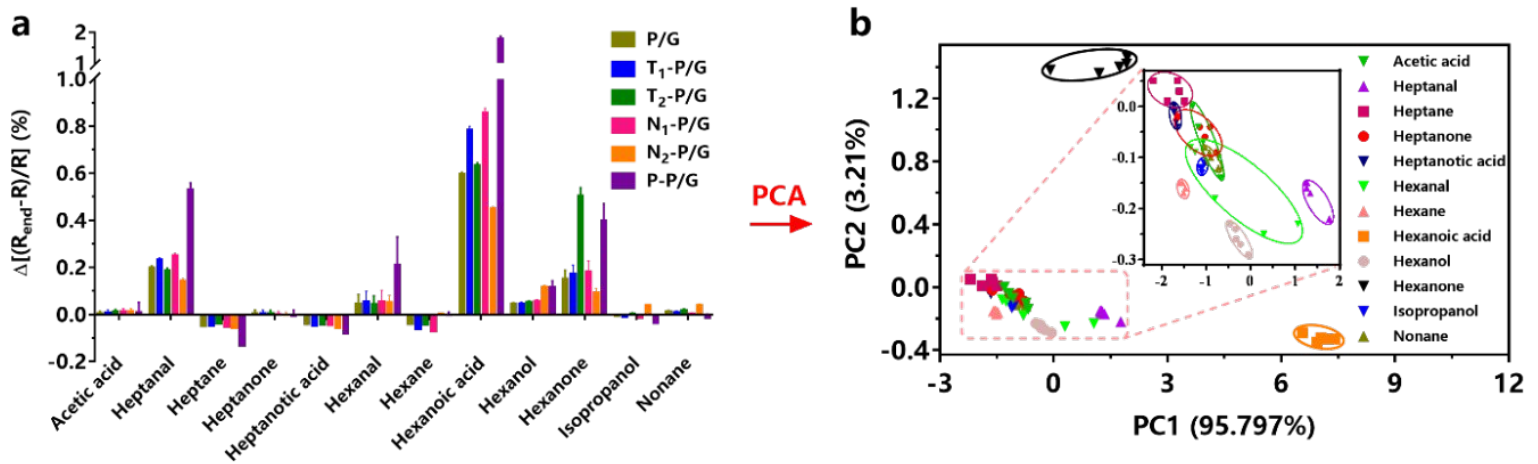

Fig. S11 The sensing performances of barcode-like sensor array (BLSA) toward VOCs. a, $\Delta\left[\left(R_{\text {end }}-R_{b}\right) / R_{b}\right]-$ response pattern of BLSA against VOCs. b, 2D canonical score plot for the $\left(R_{\text {end }}-R_{b}\right) / R_{b}$-response pattern as obtained from PCA against VOCs. 

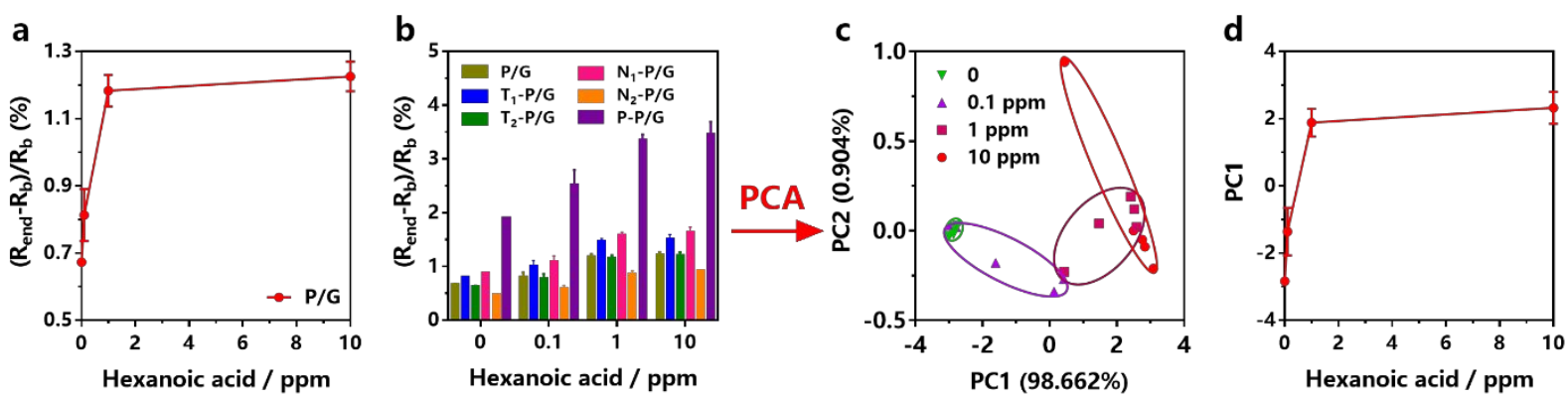

Fig. S12 a, Plot of $P / G$ ink sensors' responses to Hexanoic acid from 0 to $10 \mathrm{ppm}$. $\mathbf{b}$, $\left(R_{\text {end }}-R_{b}\right) / R_{b}$-response pattern of barcode-like sensor array (BLSA) against Hexanoic acid from 0 to $10 \mathrm{ppm}$. c, 2D canonical score plot for the $\left(R_{\text {end }}-R_{b}\right) / R_{b}$-response pattern as obtained from PCA against Hexanoic acid from 0 to $10 \mathrm{ppm}$. $\mathbf{d}$, Plot of the first discriminant factor (PC1) vs. Hexanoic acid. 